\title{
直交型害験計画の自動構成に関する提案
}

\author{
筑波大学社会工学系 藤 原 \\ 良
}

\section{Some Ideas for Computer Construction \\ of Orthogonal Arrays}

Ryoh FujI-HaRA

\section{1.はじめに}

近年コンピータが身近に使えるようになったおかげで，実験計画の計画作りに関してもコン ピュータを使って構成しようという動さが出てきた [須田（1983）, 須田・宮崎（1987）．特に， 実験計画法の中でも，直交実験と呼ばれるタイプの研究がさかんである. 基本的な方法は, [FujiHara (1978)，高橋（1979，p. 137），高橋 他（1976)]にあるように，因子を有限射影幾何の点に 割りつけ，有限射影幾何のベクトル表現を用いて，直交表を生成するといら方法である。しかし割 りつけのとき,特定の因子間に 2 次の交互作用があると仮定し，それも推定できるような值交表を 生成したい.これが割りつけを複雑なものにしている。いま行なわれている方法を簡単に述べる。 まず，次の前提をおく。

（1）因子 $F_{1}, F_{2}, \cdots, F_{m}$ の主効果は全て推定可能とする。（主効果同士又は 2 次の交互作用と交 絡しない)

（2）水準数は各因子とも素数又は素数巾 $(q)$ とする.

(3) $M=\{1,2, \cdots, m\}$ の対 $\{i, j\}, i \neq j$ の集合 $I$ が与光られ, 2 次の交互作用 $F_{i} \times F_{j},\{i, j\} \in I$ の効果が全て推定可能とする.

これらの条件は， $M, I$ そして $q$ によって特徽づけられる， $M$ と $I$ は， $M$ を頂点集合， $I$ を辺

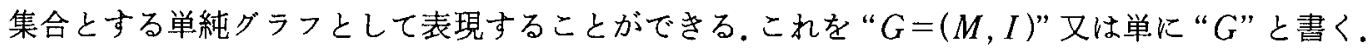
実験モデルを次のように仮定する。

$$
\begin{array}{rlrl}
y\left(r_{1}, r_{2}, \cdots, r_{m}\right)= & \mu & \text { (一般平均) } \\
& +\sum_{i \in M} \alpha_{i}\left(r_{i}\right) & & \text { (主効果) } \\
& +\sum_{\{i, j\} \in I} \gamma_{i j}\left(r_{i}, r_{j}\right) & & \text { (2 次の交互作用効果) } \\
& +\cdots & \\
& +\varepsilon\left(r_{1}, r_{2}, \cdots, r_{m}\right) & & \text { (誤差) }
\end{array}
$$

Key words: Orthogonal array, projective geometry, design of experiment, spread, matching 


$$
S=\{0,1, \cdots, q-1\}, \quad r_{i} \in S \text { とすれば, }
$$

$$
\begin{aligned}
& \sum_{a \in S} \alpha_{i}(a)=0, \quad i \in M \\
& \sum_{a \in S} \gamma_{i j}(a, b)=\sum_{b \in S} \gamma_{i j}(a, b)=0, \quad\{i, j\} \in I
\end{aligned}
$$

これらの主効果及び交互作用効果が，全て推定可能な直交表 $A$ は，次の性質を満たさねばなら ない.

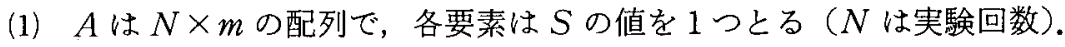

(2) $A$ のどの 2 列をとっても，S×Sの各要素が行として同数回現われる.

(3) $\{i, j\} \in I, k \neq i, j$ のき $A$ の第 $i, j, k$ の列には $S^{3}=S \times S \times S$ 要素が行として同数回 現われる。

(4) $\{i, j\},\{k, l\} \in I,\{i, j\} \cap\{k, l\}=\phi$ のとき, $A$ の第 $i, j, k, l$ 列には $S^{4}$ の各要素が行とし て同数回現われる。

このような，直交表を構成する手法として，因子 $F_{1}, F_{2}, \cdots, F_{m}$ を有限射影幾何 $P G(n, q)$ の 点に割りつける方法以外に系統的な方法はなだ知られていない。

因子 $F_{1}, F_{2}, \cdots, F_{m}$ の射影幾何への割りつけとは, 次の各条件を満たす $M$ から射影幾何の点集 合 $V$ への写像 $\varphi$ を定めることである.

(1) $\varphi$ は $M$ から $P G(n, q)$ の点集合への単射

(2) $\{i, j\} \in I$ につい, $\varphi(i)$ と $\varphi(j)$ を通る直線は $k \in M-\{i, j\}$ なるどの $\varphi(k)$ る通らない.

(3) $\{i, j\},\{k, l\} \in I$ から, $\{i, j\} \cap\{k, l\}=\phi$ なら, $\varphi(i)$ と $\varphi(j)$ を通る直線は $\varphi(k)$ と $\varphi(l)$ を通る直線と交わらない。

この割りつけを行なら方法として, 現在, 次の 2 つの方法がよく行なわれている.

\section{ランダム, 割りつけ}

$\mathrm{a}_{1}$ ） 因子にあらかじめ順序をつけて和き，その順序で割りつけを行なう．今， $F_{1}, F_{2}, \cdots, F_{m}$ の 順とする。

$\mathrm{a}_{2}$ ）射影幾何の全ての点に関する配列を用意し，割りつけ可能か不可能かのチェックをいれら れるデータ構造を用意する。

$\left.\mathrm{a}_{3}\right) F_{i}$ を割りつけるとき, 割りつけ可の点の内から，ランダムに 1 点を選び，その点に $F_{i}$ を割 りつける。

$\mathrm{a}_{4}$ ） $F_{i}$ 学割りつけたとさ，もし $F_{i}$ が $F_{j}, j<i$ との間に交互作用の存在を仮定しているとき， $\varphi(j), \varphi(i)$ を通る直線上の点を全て割りつけ不可にする。もしその点が既に不可になって いたら $\mathrm{a}_{3}$ にもどる.

$\left.\left.a_{5} ） a_{3}\right) と a_{4}\right)$ を繰り返す。もし全ての因子を割りつける前に, 割りつけ可の点が無くなったな ら，別の乱数列を用いて，F $F_{1}$ より割りつけなおす。

バック・トラックキング法

$\left.\left.a_{3}^{\prime}\right) a_{3}\right)$ で割りつけ可の点を選ぶとき，ランダムではなく，ある特定の順に選ぶ。

$\left.a_{4}^{\prime}\right) a_{4}$ )で割りつけの点がなくなったとき，1つ前に割りつけた因子を次の点に割りつけなおし て，また繰り返す（注 2 点を通る直線を求める方法は [Fuji-Hara（1978）にに述べてある.） 
これらの方法は，もちろん多項式オーダーではなく，たと党割りつけが，ある $P G(n, q)$ 上で 理論上可能でも，Gが複雑であれば，かなりの時間がかかる。この問題は，任意の単純グラフの 射影幾何への埋め込夕問題であり，近いらちに多項式オーダーのアルゴリズムが開発されるとい う望みはあまりない，たと觉ば，完全グラフ $K_{m} か ゙ P G(n, q)$ へ埋め込めるかどうかも一般には 解けていない.

ここで述べた方法は，射影幾何上の点と直線の結合関係のみを利用して，割りつけを行なって いる.もし， $a_{3}$ )や $\mathrm{a}_{3}^{\prime}$ )で選ぶ点の範囲に制約をつけることができれば，繰り返し数を減らすこと ができるはずである。そこで，ここでは射影幾何上の構造をもっと積極的に利用して割りつけを 改善する方法をいくつか提案する.

\section{2. 有限射影幾何の構造}

この節では, 割りつけに利用できそらな有限射影幾何 $P G(n, q)$ の構造に関して述べる. コン ピュータを使って割りつけの対象とする射影幾何は，一般に 3 次元以上であると考えてよい，平 面の場合は，田ログラフのリストなどもあり，コンピュータを利用しなくても，割りつけること が可能である.

\subsection{Spread}

Spread とは, 互いに交わらない直線の集合で, 幾何上のどの点も, そのどれかの直線上にある. 例 $1 P G(3,3)$ の点を $G F(3)$ 上の最小多項式

$\alpha^{4}=\alpha+1$ を用いて構成すると，原始根 $\alpha$ の乗の形を $\alpha^{0}, \alpha^{1}, \cdots, \alpha^{39}$ で表現でさる，いま点 を巾のみで表現すると, $P G(3,3)$ 上の全ての直線は

$\begin{array}{llllllllllllllll}0 & 1 & 4 & 13 & 0 & 2 & 17 & 24 & 0 & 6 & 11 & 32 & 0 & 10 & 20 & 30\end{array}$

の 4 本の直線を元に+1 $(\bmod 40)$ することによりサイクリックに生成できる [高橋 $(1979)$ 参照].

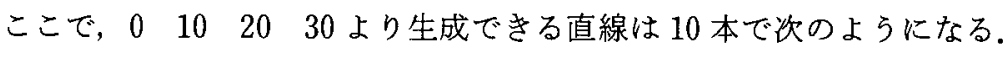

$\begin{array}{llllllll}0 & 10 & 20 & 30 & 5 & 15 & 25 & 35 \\ 1 & 11 & 21 & 31 & 6 & 16 & 26 & 36 \\ 2 & 12 & 22 & 32 & 7 & 17 & 27 & 37 \\ 3 & 13 & 23 & 33 & 8 & 18 & 28 & 38 \\ 4 & 14 & 24 & 34 & 9 & 19 & 29 & 39\end{array}$

この 10 本の直線は互いに交わらず，かつ $P G(3,3)$ の全ての点を被覆しているので spread で ある。

spread の存在は，nが奇数であることが必要十分条件である [Hirschfeld (1983) 参照]. $P G(n, q)$ の spread に含まれる直線の数は， $\left(q^{n+1}-1\right) /\left(q^{2}-1\right)$ 本である. 次元 $n$ が偶数のとき は spread は存在しないが, partial spread と呼ばれる直線の集合がある, partial spread とは, 単 に互いに交わらない直線の集合である. 次元が偶数 $(2 k)$ のときの partial spreadの直線の最大数 は $\sum_{i=1}^{k-1} q^{2 i+1}+1$ となる [Beutelspacher (1980)]. 
spreadの中にもいくつかの興味深い構造がある。多を 1 つの spreadとする。もし，yのq+1 本の直線集合 $\mathscr{R}$ が次の性質を満たすなら， Rを regulus と呼ぶ：

もし, $y$ 以外の直線 $l か ゙ \mathscr{R}$ 直線と交わるなら, $l$ は $\mathscr{R}$ 全ての直線と交わる( $l$ はを横 断するといら).

例 2 例 1 のpread より

$$
\mathscr{R}=\{\{0102030\},\{1,11,21,31\},\{4,14,24,34\},\{13,23,33,3\}\}
$$

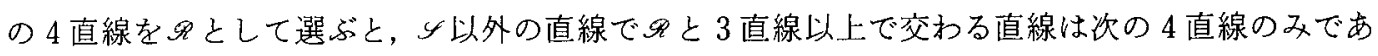
る.
$\begin{array}{llll}0 & 1 & 4 & 13\end{array}$
$\begin{array}{llll}10 & 11 & 14 & 23\end{array}$
$\begin{array}{llll}20 & 21 & 24 & 33\end{array}$
$\begin{array}{llll}30 & 31 & 34 & 3\end{array}$

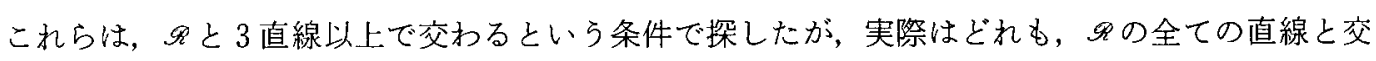
わっている。このことから化 regulusであるとい方るこれを図示すると次のようになる。

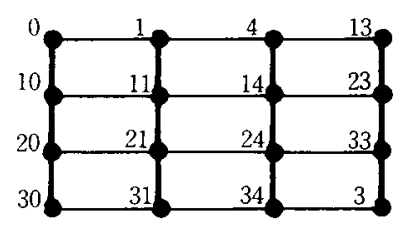

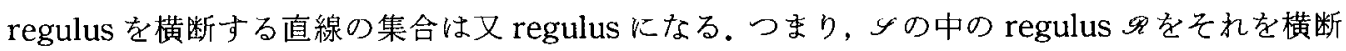

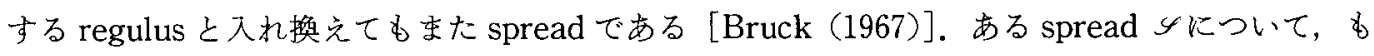

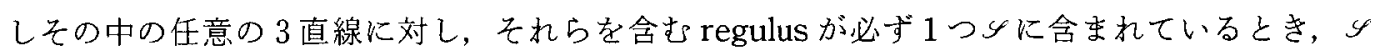
は regular spreadと呼ばれる，PG(3，q)には reguler spreadが存在することが知られている [Bruck (1967)].

例 1 の spread は regular spreadである。一般に, 例 1 と同様に, $P G(n, q)$ の点を整数表現す ると, $n$ が奇数のとき, 点集合

$$
\{0, d, 2 d, \cdots, g d\} \quad d=v /(q+1), v=\left(q^{n+1}-1\right) /(q-1)
$$

は, 使った最小多項式によらず, 1 つの直線である.この直線から+1 $(\bmod v)$ によってサイクリッ クに生成される $d$ 個の直線は spreadになる [高橋（1979）参照］ｎ=3のとき，この spread は regularである。また $n=3 の と き の$ regular spreadの分類は完全にされて㧍，全ての regular spread をつくすことも可能である [Beutelspacher (1974)].

regular spread $\mathscr{S}$ の直線を点, regulusをブロックとすれば, regular spreadの定義より，任 意の 3 点（3 直線）を含むブロック（regulus）が必ず1つ存在することがいえるので，これはブ ロック・デザインの用語でい5，3-designである.

次に互いに共通な直線を持たない複数の spreadに関して述べょう.もし $P G(n, q)$ の全ての直 線が $r$ 個の spread $\mathscr{S}_{1}, \mathscr{S}_{2}, \cdots, \mathscr{S}_{r}, r=\left(q^{n}-1\right) /(q-1)$ に分割できるとき，その分割を resolutionあるいは parallelism と呼ぶ. $P G(n, q)$ の parallelismは $n=2^{i}-1, i=2,3, \cdots の と き と$, $q=2, n=$ odd のときしか存在が知られていない [Baker (1976), Beutelspacher (1974)].これ 
らのケース以外でも，互いに共通直線を持たない spreadをいくつか構成することがでさる。いま のところ，次のことが言える：

$P G(2 k+1, q), k \geq 1$ で, 少なくとも $q^{2}+q+1$ 個の互いに共通直線を持たない spread が存在 する。

partial spreadに関しても，互いに共通直線を持たない $2 つ の$ partial spread は存在するが，そ のときカバーされている点集合が同じになるようにでさるかどうかは未だ解決されていない．

\subsection{Fan}

$P G(n, q)$ の $t$ 次元部分空間を $t$-flat と呼ぶ. 特にその中で， 0, 1, 2-flat 各々点，直線，平 面と呼ぶ. 今, $T$ を $t$-flat とする。 $u$-flat の集合 $U_{1}, U_{2}, \cdots, U_{l}$ が $U_{i} \cap U_{j}=T, i \neq j$ を満た 寸とさ，その $u$-flat の集合をfan と呼ぶ. 射影幾何の性質より $u \geqq t+1$ であることはすぐにわか る。最も簡単な fan はある1点を共有する直線の集合である。これはまた pencil とも呼ばれる。

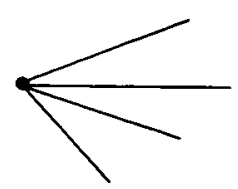

fan 中の $u$-flat の個数 $l$ の最大数は

$$
\left(q^{k+1}-1\right) /(q-1), \quad u=n-k, k \geq 1
$$

である。

\section{3. 割りつけ}

第 2 節で述べた, 射影幾何上の構造を利用して, 割りつけ法を改善するためのいくつかの案を この節で述べる.

\subsection{Spread の利用}

spread $\mathscr{゙}$ 利用するため，まず，主効果と 2 次の交互作用効果を表現したグラフ $G$ を考える. (グラフ理論上の用語は Bondy and Murty（1976）又はWilson (1985) を参照)

(i) グラフ $G$ の上でまず最大マッチングを見つける.

グラフのマッチングとは，辺の部分集合で，互いに共通点を持たないものをいう，最大マッチ ングとはマッチングの最大辺数を持つものをいら.最大マッチングを見つけるには, 多項式オー ダのアルゴリズムが知られている [Edmond (1965)].

(ii）今 $G$ の最大マッチングをルとしたとき，割りつけを行う原則として，ルに含まれる辺 $\boldsymbol{e}=\left\{v_{1}, v_{2}\right\}$ に対して spread $\operatorname{s}$ の゙れかの直線上に点 $v_{1}, v_{2}$ を割りつける.

このとき, 2 つの問題が出てくる. 第 1 は M辺 $\boldsymbol{e}$ をのどの直線に割りつけるか, 第 2 に, そ の直線上のどの点に $v_{1}, v_{2}$ を割りつけるかといらことである。 まず第 1 の問題を解決するために 
次のことを行なう。

(iii）グラフGを最大マッチングルの全ての辺について $G$ を縮約（contruct）する. グラフ $G$ を辺 $\boldsymbol{e}=\left\{v_{1}, v_{2}\right\}$ で縮約するとは, 点 $v_{1}, v_{2}$ を 1 つの点 $v^{\prime}$ としてしまい, 辺 $\left\{v_{1}, v_{2}\right\}$ は取り除く、 $v_{1}$ 又は $v_{2}$ に結合していた $G$ の他の辺は $v^{\prime}$ に結合するグラフ $G^{\prime}$ にする. $G^{\prime}$ は多 重辺を持ったグラフとなる.

(例)
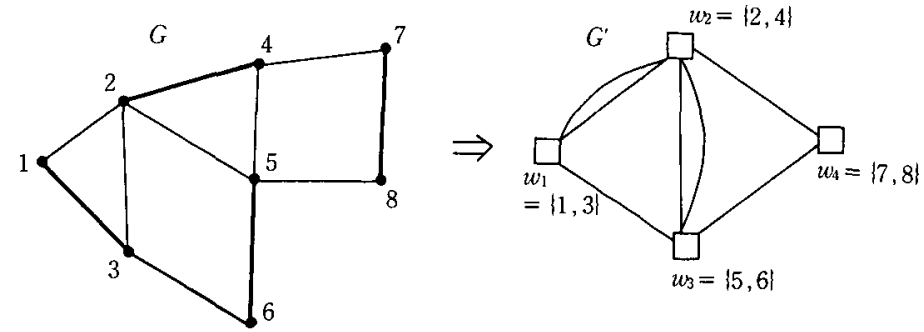

$\mathscr{M}=\{\{1,3\},\{2,4\},\{5,6\},\{7,8\}\}$ でコントラクト

もしＳかが regular spreadなら, 任意のSの 3 直線に対して，それらを含む regulus が存在す る. そこで, regular spreadを用いるときは， $G^{\prime}$ で最も複雑な 3 点, 上の例では $w_{1}, w_{2}, w_{3}$ が regulus に割りつけできなければ $G$ は岀への割りつけは不可能である。 またそれが可能の時，そ の他の $G^{\prime}$ の点, 例总ば $w_{4}$ は $w_{1}, w_{2}, w_{3}$ を割りつけた regulus 以外の直線に割りつけるのが楽で

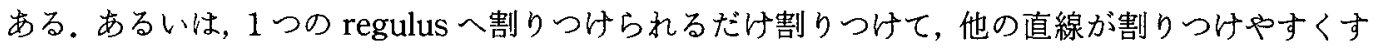
ることもできる。

次に, 縮約されたグラフ $G^{\prime}$ の多重辺をもら少し細かく分類してみよう，G'で多重辺となった 場合，もとのグラフGでは，同型を除いて次のような結合関係になっている.

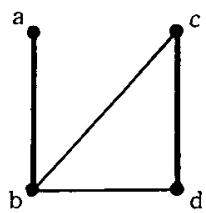

(1)

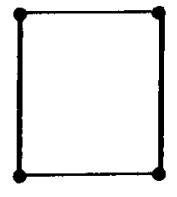

(2)

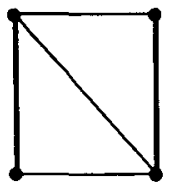

(3)

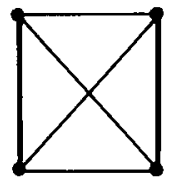

(4)

エがもし，regular spreadなら，どのSのどの 3 直線についても，それを含む regulusが必ず 1 つ存在する。このことから $\mathscr{S} 2$ 直線については，とれらを含む regulusは $q+1$ 個 $(P G(3, q)$ で）存在する。このことから，(1)の typeでは，\{a，b\}，\{c，d\}を为の 2 直線に割りつけたとき， $\{b, c\}$ と $\{b, d\}$ は異なる regulus を横断する。 これら 2 つの regulusへはルの他の辺は割りつけ ることはできない（2)の typeでは， $\{a, c\},\{b, d\}$ が同一の regulus を横断するように割りつけ られる. 同様に，(3)，(4)では共に 2 つの regulusのみを横断するように割りつけられる。このよ らにソの直線をできるだけ, 割りつけ可能のまま残すよらにしていけば,上り複雑なグラフも, 割 りつけやすくなるであろう。 


\section{2 共通直線を持たない 2 つの spread の利用}

第 2 節で, 互いに共通直線を持たない 2 つの spread 又は partial spread が存在することを述べ た。ここで，それを割りつけに利用することを提案する。

（i）共通直線を持たない $2 つ の$ spread $\mathscr{S}_{1}, \mathscr{S}_{2}$ から次のよらな 2 部グラフ $H$ を作る.

$\mathscr{S}_{1}, \mathscr{S}_{2}$ の直線の集合を各々 $V_{1}, V_{2}$ とする.そして，Hは $V_{1} \cup V_{2}$ を点とし，Hの辺に関し ては， $v_{1} \in V_{1}, v_{2} \in V_{2}$ に対し， $v_{1}$ と $v_{2}$ が交わるとき，そしてその時に限り $H$ の辺とする.

もし, $\mathscr{S}_{1}, \mathscr{S}_{2}$ が共に spreadなら, $H$ は次数 $q+1$ の正則 2 部グラフとなる. 又 $\mathscr{S}_{1}, \mathscr{S}_{2}$ が partial spread なら最大次数 $q+1$ の単なる 2 部グラフである.

(ii) グラフ $G$ より共通辺を持たない 2 つの最大マッチング $\mathscr{M}_{1}, \mathscr{M}_{2}$ を見つける，そして次の

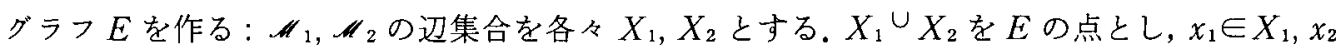
$\in X_{2}, x_{1}$ と $x_{2}$ が $G$ で共通点を持っているときそして，そのときに限り $E$ で辺 $\left\{x_{1}, x_{2}\right\}$ が存在 する。

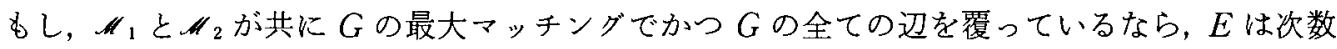
2 の正則 2 部グラフとなる。つまりこのとき $E$ はサーキットの集まりとなる。もし $G か ゙$ 連結グラ

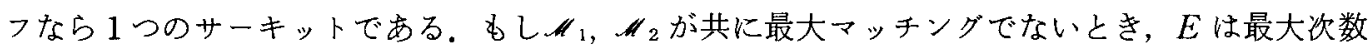
2 の 2 部グラフになる.

(iii）次のよらなグラフ $E$ からグラフ $H$ への準同型写像 $\pi$ を考觉る：

(a) $\pi: X_{1} \cup X_{2} \rightarrow V_{1} \cup V_{2}$

(b) $\{x, y\}$ が $E$ の辺であり，そのときにかぎり $H$ の辺 $\{\pi(x), \pi(y)\}$ が存在する.

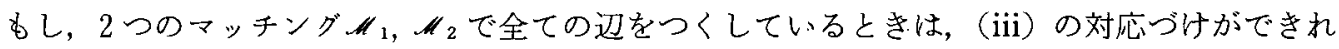

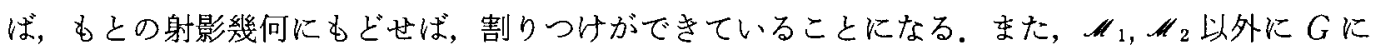
点又は辺が残っているときは，その点に関して，従来の方法で割りつけを試みることができる.但 し，もしグラフ Gの次数の分布にかなりバラッキがあるとさは最大マッチングで被覆されない点 が増えるのでこの方法はあょり向かない。

\section{$3.3 \operatorname{fan} の$ 利用}

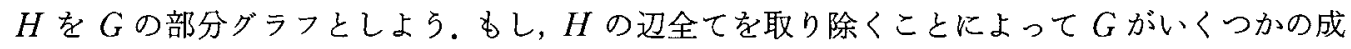
分からなる非連結グラフとなるとき， $H$ をカット部分グラフと呼ぶ.

(例)

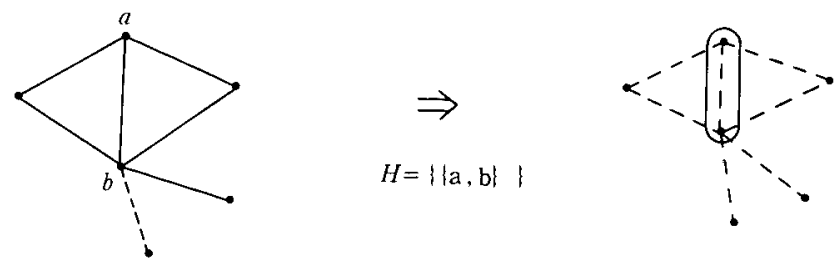

次の原則に従ってGを $P G(n, q)$ の fan に割りつける.

（i）カット部分グラフを fanの共通部分に割りつけ，非連結成分を他の互いに交わらない部 分にそれぞれ割りつける。 
(例)
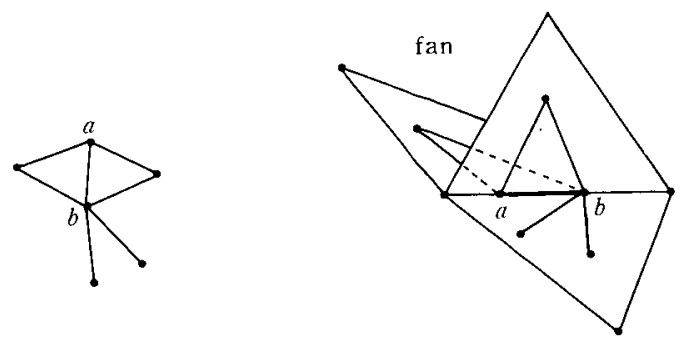

例觉ば $P G(3,3)$ fan は下図のよらな pencil 又は plane fanの 2 種類しかないので, カット 部分グラフ $H$ は 1 つ点からなるグラフか, 又は 2 点と 1 つの辺からなるグラフでなくてはな らない.
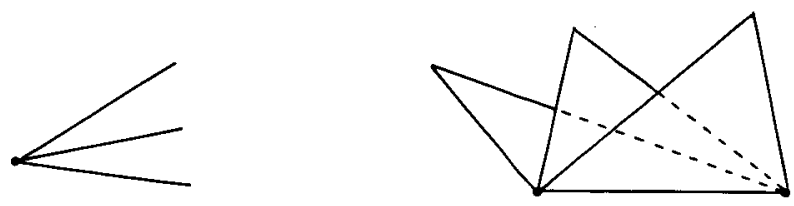

$H$ が点のときは，Gはスター型でなければならない。

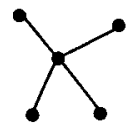

$$
\text { スター型グラフ }
$$

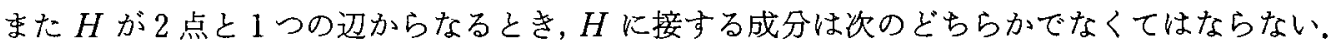

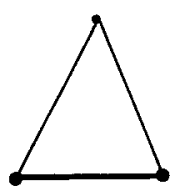

$H$
高々 $q$ 本

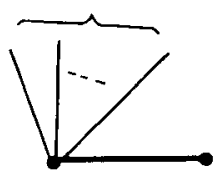

また成分の個数も fanに含まれる $t$-flat の個数以下でなけれぱならない。

\section{4. おわりに}

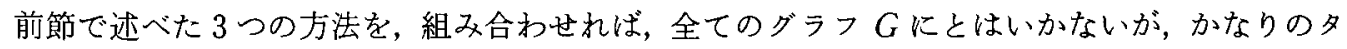
イプのグラフに適応できるはずである. spread 又は partial spread を利用するときは, regulusの 情報をデータベースとして持って扔くと，縮約された点を spreadのどの直線に割りつけるとよ 
いかといらことを早く見つけることができる，regular spreadの場合（ $P G(3, q)$ のき）は $3^{-}$ designになるので，その block 情報を持っていればよいまた regulus を横断する直線の情報も 持っていれば，助かるはずである. partial spreadに関しては，どの直線が regulus かあらかじめ 調べて，お汭えて扔く必要がある。

ここで述べた案は，1節の $\mathrm{a}_{3}$ ) や $\mathbf{a}_{3}^{\prime}$ ) で点を選ぶときに, spread, あるいはfan上に制限するこ とによって，サーチを早くしょらという考光である。当然制限をもうけることによって，1節で述 ベた従来の方法では割りつけ可だが, 3 節の方法では不可能,つまり実用的な時間では終わらない 場合もでてくる。もちろん従来の方法も割りつける因子に順序をつけているので，完全サーチに はなっていない，どんなケースが従来の方法より早くなっているのか，又その逆はどんなケース かを，須田（1983）や須田・宮崎（1987）での実験データと比較するのは興味ある課題である.

\section{参 考 文 献}

Baker, R.D. (1976) : Partitioning the planes of $A G_{2 m}$ (2) into 2-design, Discrete Math. Vol. 15, 205-211 Beutelspacher, A. (1974): On parallelisms in finite projective spaces, Geometriae Dedicata Vol. 3, 35-40 Beutelspacher, A. (1980): Blocking and partial spreads in finite projective spaces, Geometriae Dedicata Vol. $9,425-449$

Bondy, J.A. and Murty, U.S.R. (1976): Graph Theory with Applications, Gresham Press

Bruck, R.H. (1967) : Construction Problems of Finite Projective Planes, Proc. Conf. Combinatorics, held at the University of North Carolina at Chapel Hill University of North Carolina Press

Edmond, J. (1965) : Path, tree and flowers, Canad. J. Math. Vol. 17, 449-467

Fuji-Hara, R. (1978): On automatical construction for orthogonal design of experiments, Rep. Stat. Appl. Res., JUSE, Vol. 25, No.1, 13-25

Hirschfeld, J.W.P. (1979): Projective geometries over Finite Field, Oxford University Press

Hirschfeld, J.W.P. (1986) : Finite Projective Space of Three Dimension, Oxford University Press

須田健二 (1983)：「パンコンによる直交実験の計画と解析」日科技連品質管理 Vol. 34 月月臨時增刊号 803807.

須田健二, 宮崎晴夫（1987）：「直交配列を用いた実験計画に括ける要因割りつけのコンピュータ・アルゴリズム について」日本経営工学会誌, Vol. 37, No. 6, 345-352.

高橋磐郎 (1979): 「組合せ理論とその応用」岩波全書.

高橋啟郎, 藤原 良, 杉本英二, 須田健二, 神保雅一 (1976): 「直交実験の自動計画と Maximal 3, 4-linearly independent set」京都大学数理解析研究所講究録, No. 285, 13-22.

Wilson, R.J. (1985)：Introduction to Graph Theory, 3ed（訳：斉藤伸自, 西関隆夫「グラフ理論入門」近代科 学社)

(1987 年6月 26 日受付 1988 年 1 月 29 日最終修正)

著者連絡先：茨城県新治郡桜村 筑波大学社会工学系 